\title{
Health-Related Quality of Life or Quality of Medical Service? Current challenges for family doctors
}

\author{
KRZYSZTOF KANECKIA, B, D-F, ANETA NITSCH-OSUCH'A, B, D, E, PIOTR ZBIGNIEW TYSZKO A, B, D-F
}

Department of Health Care, Medical University of Warsaw

A - Study Design, B - Data Collection, C - Statistical Analysis, D - Data Interpretation, E - Manuscript Preparation, $\mathbf{F}$ - Literature Search, $\mathbf{G}$ - Funds Collection

Summary Maximizing Health-Related Quality of Life (HRQoL) is one of the most important goals in the work of the family doctor. Providing a high quality of medical services (QMS) should be among the most important challenges in primary health care organizations (PHCOs). In practice, these two areas of activity require continuous improvement, and can complement each other and enhance their mutual impact on the health of patients. The objective of this article is to present selected areas of HRQoL and QMS improvement in the practice of a family doctor, which might contribute to patients' health, to cost reduction, and to a beneficial reposition of a health center within the medical service market. The paper presents proposals for improving HRQoL and QMS through the use of data from questionnaires filled out by patients, through the cooperation of all the people involved in the delivery of medical services, through adaptation of the IT infrastructure to meet the needs of PHCOs, and through improvements in quality as the result of a process model. QMS is of great importance, especially for both consumers and providers of medical services, including PHCOs. Improvement in quality should be considered as operating on both HRQoL and QMS. This paper presents strategies for selected areas that may contribute to improving QMS, both with respect to the opinions of patients and the functioning of PHCOs.

Key words: health-related quality of life, family medicine, quality of medical services.

Fam Med Prim Care Rev 2016; 18(3): 382-386

\section{Background}

Maximizing Health-Related Quality of Life (HRQoL) is one of the most important goals in the work of the family doctor; similarly, providing a high quality of medical services (QMS) should be one of the most important challenges for primary health care organizations (PHCOs). In practice, these two areas of activity require continuous improvement; they may also be complementary and enhance each other's impact on the health of patients. Improving HRQoL is a challenge for family physicians, especially in the context of the limited treatment possibilities, the aging of the population, and the increasing expectations of patients towards the health care system. The need for research into and improvement in HRQoL also results from the legal and ethical obligations of the family doctor.

As a part of medical practice, a family doctor provides medical services to which quality can be attributed (QMS). At the same time, the medical services provided by the family doctor can induce changes in HRQoL of patients and, in this sense, these two categories of quality can be seen to be interrelated.

HRQoL assessment is the starting point for further activities that aim at quality improvement. HRQoL improvement can be individually targeted to each patient. The areas of activity dedicated to HRQoL improvement in PHCO may not only be patient-oriented, but also system-oriented. Indirect determinants of the effectiveness of these activities may be related to the assessment of QMS. This article presents the possibility of assessing HRQoL; however, the activities suggested here for aiming at improvements in HRQoL in PHCOs will be related to activities in the area of QMS improvement. QMS improvement in $\mathrm{PHCO}$ is required by law, but can also be an asset in gaining competitive advantage in the medical services market and in reducing costs in the long term.

\section{Definition of HRQoL}

It is very important to appropriately define HRQoL. However, this has not been an easy problem for researchers. The multiplicity of definitions of HRQoL implies a diversity of approaches to this term.

Quality of life may be defined as an individual's perception of his or her position in life in the context of the cultural and value systems in which he or she lives and in relation to personal goals, expectations, standards, and concerns [1].

Quality of life in clinical practice has eight potential areas of measurement that can be used to identify and prioritize problems, facilitate communication, screen for potential problems, identify preferences, monitor changes or respond to treatment, and train new staff [2].

HRQoL can be defined as the subjective assessment of the impact of disease and its treatment on the physical, psychological, social, and somatic domains of human functioning and well-being [3].

It is worth noting that, in order to ensure a high standard of care, it is necessary to monitor how patients' needs are met [4].

Most patients stated that they should evaluate the quality of health care; however, fewer patients declared their readiness to actually participate in studies focused on the quality of care [5].

As patients play a unique and important role as evaluators of quality of care, it can be concluded that the opinion of patients should be taken into account by health care managers [6]. Another study indicated the need for significant in- 
volvement of patients in the development and improvement of health care [7].

Recent medical data have confirmed the usefulness of HRQoL assessment in primary health care. A longitudinal study of the determinants of HRQoL in older primary care patients showed that motivating patients to increase their weekly physical activity and to focus on preserving their ability to walk is a promising approach to improving HRQoL in older age [8]. In another large study focused on HRQoL in primary care patients, it was reported that, in order to enhance the functional capacity of primary care patients with co-existing chronic disease and depressive symptoms, health care interventions should be aimed at improving the physical aspects of HRQoOL [9].

\section{Quality of medical services (QMS)}

Quality of care is the degree to which health services for individuals and populations increase the likelihood of desired health outcomes and are consistent with current professional knowledge [10].

With a favorable outcome as one characteristic, the American Medical Association (AMA) believes that medical care of high quality should: (a) produce the optimal possible improvement in the patient's physiological status, physical function, emotional and intellectual performance, and comfort at the earliest time possible, and consistent with the best interests of the patient; (b) emphasize health promotion, prevention of diseases or disabilities, and early detection and treatment of such conditions; (c) be provided in a timely manner, without undue delay, inappropriate curtailment or discontinuity, or unnecessary prolongation of such care; (d) seek to achieve conscious cooperation with and the participation of the patient in the care process and in making decisions concerning that process; (e) be based on accepted principles of medical science and the proficient use of appropriate technological and professional resources; ( $f$ ) take into account patients' sensitivity to the stress and anxiety that can be generated by an illness, with concern for patient's overall welfare; (g) make efficient use of technology and other health system resources to achieve the desired treatment goal; and (h) be sufficiently documented in the patient's medical record to enable continuity and evaluation of care [11].

Notwithstanding the particularities of the definitions, quality should be approached from the perspective of generally accepted efficiency features of a health care system. These features may be divided into (i) features related to the patient and (ii) features related directly to the internal efficiency of the system.

(i) Traditional efficiency features directly related to the patient are availability, continuity, and comprehensiveness. Availability reflects the possibility of obtaining health care services at a time and place convenient for the patient. This is determined by the presence of a particular service in the offer of medical services, the number, type and location of healthcare centers, as well as work organization, including the rules of registration for a medical service, transportation routes and connections, and the costs of obtaining a medical service, broadly understood [12].

The continuity of a medical service is of significant importance from the perspective of the efficiency of diagnostic and therapeutic procedures and psychological relations between a doctor and a patient. From the point of view of a recipient of a medical service, the continuity of a medical care can be analyzed in two dimensions: first, in terms of life, from birth to death, and second, in terms of health condition, from full health through various phases of an illness, to the total lack of health, which means the end of life [13].

The comprehensiveness of health care relates to a health care organization's feasibility and readiness to deal with each and every health problem of a person entitled to health care [13].

The Health for All program from the year 2000, in relation with the Declaration of Alma-Ata, emphasized the adequacy of health care, understood as the adjustment of medical services to health needs [14, 15]. Recently, the postulate of long-term stability has been introduced in European Union documents [16]. In the case of primary health care, special attention is given to preventive care [17].

(ii) The features relating to the internal efficiency of the system are those not revealed directly in connection with providing health care services to a patient, and are not exposed to the patient - although they have a direct influence on QMS. A good example of such a feature might be a management style in a health care center, which can indirectly influence the quality of relations with a patient through the satisfaction or dissatisfaction of medical staff. Another example might be an effective system of informative or technical support, which provides rapid access to the medical materials, tools, and equipment needed for the provision of medical services. Last but not least, hospital-acquired infections and medical services connected therewith might also be analyzed from the context of the internal efficiency of the system.

\section{Objectives}

The objective of this article is to present selected areas of HRQoL and QMS improvement in the practice of a family doctor which might contribute to patient health, cost reduction, and the strengthening of a health center's position in the medical services market.

\section{HRQoL and QMS: areas for improvement}

\section{Obtaining information on HRQoL}

It can be argued that obtaining information on HRQoL directly from a patient is an integral element of HRQoL improvement.

Although typical paper survey forms are very useful in the assessment of HRQoL, they require the dedication of a certain amount of time, both on the part of the pollster and the patient. Survey content can be adjusted to the needs of PHCOs; however, any modifications might limit the possibility of comparing survey results from different periods.

Surveys are particularly useful when there is a need to improve the quality of health care provided to a patient, but where it is impossible to specify areas or methods for the improvement of medical services on the basis of available data concerning patients' expectations - such as complaints, opinions, and suggestions related to the functioning of $\mathrm{PH}$ COs. A survey should also be used whenever it is expected that the answers provided by respondents will make it possible to choose the better of at least two options that are significant for improving HRQoL. Apart from this, a survey should include the following elements: assessment of factors that have a real influence on HRQoL and an appropriate range of answers. The structure of the survey should be clear. Both the questions and the form of the answer should be comprehensible to the patient. It is also advisable to consider obtaining information on HRQoL via electronic means; this alternative might be an attractive and less inconvenient form of transferring information. Data obtained through electronic forms provides information on patients' expectations and could be significant for improving quality in health care units [18].

HRQoL measuring instruments may be generic or disease-specific. Generic instruments have the advantage of being applicable to all individuals, irrespective of the type or number of their illnesses; however, they may not be sensitive to some problems unique to particular diseases. Furthermore, the results of disease-specific instruments are difficult to in- 
terpret in people with multiple diseases. In deciding what health outcome measures to use, family doctors need to consider whether the measurement tools will be for use in all types of general practice, or only in specific areas, such as with elderly patients [19]. All HRQoL instruments, however, must be valid and have high reliability and responsiveness. Validity ensures that an instrument measures what it is supposed to measure. Reliable instruments are able to reproducibly differentiate between subjects. Responsive evaluative measures are able to detect important changes in HRQoL during a period of time, even if those changes are small. HRQoL measures should also be interpretable, meaning that the differences in scores that correspond to small, moderate, and large HRQoL changes are easily identifiable [20].

Surveys might be supported with a cumulative and periodic assessment of the needs and expectations of patients prepared by medical personnel and submitted directly to the management at meetings on improving health care quality.

\section{Process approach to the improvement of QMS}

The classic approach to the quality of medical services perceives quality as an integrated model consisting of structure, process, and outcome [21]. Given the challenges faced by family doctors, process may be one of the most attractive areas for QMS improvement.

The proper identification of processes is a key element of the process approach to improving QMS. Each activity associated with the functioning of a health care unit can potentially influence the development of QMS. A challenge for PHCOs is to select processes for identification and objective measurement without incurring a significant burden on the organization's resources. Any process that is chosen for analysis and is of importance both to the functioning of the organization and to the performance of activities aimed at improving quality should be modified to prevent the allocation of resources by the organization that would undo the potential benefits from the quality improvement. Importantly, it should always be possible to compare QMS results before and after the modification of a process. Patient registration for an appointment at a family doctor is an example of a process that could be considered in QMS improvement. This process might consist of the following activities:

1) explanation to the patient of the medical services offered,

2) patient identification

3) determination of the patient's entitlement,

4) determination of the possible dates for the medical service,

5) provision of the medical service,

6) determination of the dates of follow-up medical services, if necessary.

Under the process approach, improvements in particular stages of medical service provision, no matter how small, can considerably influence the final effect - i.e., the level of QMS. However, improvement within a few processes can be eliminated through negligence within a single process or a drop in efficiency within yet another process. Consequently, in order to obtain significant benefit from the improvement of QMS, particular care must be taken of the efficient functioning of all processes associated with the performance of a medical service.

\section{Team work}

The analysis of HRQoL and QMS constitutes a starting point for further activities, including activities undertaken by family doctors, which aim at improving the functioning of a PHCO. Meetings between the management and employees of a health care unit should be held regularly to set priorities for further activities, as another element of the improve- ment of HRQoL and QMS, since they are very good matches for the process of continuous quality improvement. Regular meetings can facilitate a faster exchange of information and integration between staff and management. We believe such an outlook on quality improvement is among the most important challenges in the daily practice of family doctors. It is worth noting that, for an organization, quality improvements might be perceived not only as ends in themselves, but also as a way of functioning. It can be stated that the approach to the improvement of quality described here is what led to the development of the Total Quality Management (TQM) concept [22], which can be defined as a "way of managing the organization, focused on quality, based on the participation of all members of the organization and aimed at achieving long-term success through customer satisfaction and benefits to all members of the organization and for society" [23].

\section{Promptness and flexibility in adjusting to changes in health care}

It can be argued that flexibility in adjusting to constantly changing conditions for the functioning of PHCOs, especially regarding the work of medical staff, constitutes another important challenge for family doctors. In these times of frequent changes in health care - when the list of reimbursed drugs is updated every few months, legal provisions regulating family doctors' work are subject to frequent modifications, and the conditions of doctor's work (including salary and responsibility) are subject to unpredictable changes - developing one's own methods of handling a rapidly changing environment is an appropriate strategy. Such a strategy should not only protect a PHCO against deteriorations in QMS, but should also be dynamically adjusted to patients' needs. The informatization of processes that support the performance of medical services is one method suggested for work improvement. However, informatization itself cannot guarantee success. It is only after IT systems have been dynamically adjusted to the rapidly changing environment that the requirements necessary to improve QMS can be fulfilled. Thus, the dynamic adjustment of IT systems might contribute considerably to improving patients' HRQoL. Changes in IT infrastructure in current health care systems could apply to both hardware and software.

Alterations, including software updates, might be necessary because of legal, administrative, and economic conditions. Implementation of software that supports the work of family doctors and reduces the risk of the occurrence of unfavorable medical, administrative, legal, and financial events might also be required. Such changes should also apply to database updates for solutions such as electronic medical reports form ZUS ZLA or the DiLO Card.

In the process approach to the improvement of QMS, special attention should be drawn to the possibility (and sometimes necessity) of implementing changes in the existing IT infrastructure. This might be applicable, for example, to improving the management of waiting lists for a medical service or changes with regard to the transfer of medical data between health centers.

\section{Summary}

In conclusion, it should be emphasized that family doctors, in attempting to improve HRQoL, deal directly with patients' expectations (improvement in HRQoL) and indirectly with activities aimed at QMS improvement in PHCOs.

Activities aiming at improvements in quality should be undertaken with consideration of the fact that improvements in QMS need to be reflected in improvements in HRQoL. We have here presented selected activities in particular 
areas that might contribute to an increase in the quality of medical services, as perceived by patients, and from the perspective of the functioning of PHCOs.

\section{Conclusions}

In order to improve HRQoL and QMS, special attention needs to be drawn to the following aspects of the work of a family doctor:

1. In order to achieve high HRQoL and QMS, it is of key importance to obtain information from patients, especially with the use of electronic communication forms.

2. All people engaged in the performance of services within the framework of primary health care should also be engaged in improving HRQoL and QMS. Among the methods suggested, meetings of medical staff and management of PHCOs should be given priority.

3. An important element in the process of HRQoL and QMS improvement is implementing the process approach. Appropriately identifying significant processes and improving them can constitute a key element of success in the practice of a family doctor.

4. These days, constant adjustment to the rapidly changing environment is a prerequisite for improving HRQoL and QMS. IT systems that allow rapid adjustments to be made to hardware and software in response to changing conditions should play a significant role here.

Source of funding: This work was funded by the statutory activity of Medical University of Warsaw.

Conflict of interest: The authors declare no conflict of interests.

\section{References}

1. WHOQoL: Measuring Quality of Life. Introducing the WHOQoL instruments [cited 26.04.2016]. Avaible from URL: http:// www.who.int/healthinfo/survey/whoqol-qualityoflife/en/.

2. Higginson IJ, Carr AJ. Measuring quality of life - using quality of life measures in the clinicalsetting. BMJ 2001; 322(7297): 1297-1300.

3. Revicki D, Osoba D, Fairclough D, et al. Recommendations on health-related quality of life to support labeling and promotional claims in the United States. Qual Life Res 2000; 9(8): 887-900.

4. Pawlak A. Jakość świadczonej opieki w ośrodkach całodobowego pobytu dla osób w wieku podeszłym. Fam Med Prim Care Rev 2015; 17(3): 197-201.

5. Marcinowicz L, Gugnowski Z, Strumiło J, et al. Czy pacjenci chcą oceniać jakość opieki zdrowotnej? Krótki sondaż wśród pacjentów. Fam Med Prim Care Rev 2015; 17(1): 28-32.

6. Coulter A. The autonomous patient. Ending paternalism in medical care. London: The Nuffield Trust; 2002: 6-8, 115.

7. Mockford C, Staniszewska S, Griffiths F, et al. The impact of patient and public involvement on UK NHS health care: a systematic review. Int J Qual Health Care 2012; 24(1): 28-38.

8. Eisele M, Kaduszkiewicz H, Konig HH, et al. Determinants of health-related quality of life in older primary care patients: results of the longitudinal observational AgeCoDe Study. Br J Gen Pract 2015; 65(640): e716-e723.

9. Chin WY, Choi EP, Wan EY, et al. Health-related quality of life mediates associations between multi-morbidity and depressive symptoms in Chinese primary care patients. Fam Pract 2016; 33(1): 61-68.

10. Lohr K, ed. Committee to Design a Strategy for Quality Review and Assurance in Medicare. Medicare: A strategy for quality assurance. Vol. 1. Washington, DC: National Academy Press; 1990.

11. American Medical Association. Quality of Care - Essentials and Guidelines for Quality Assessment 2011 [cited 11.09.2016]. Avaible from URL: https://searchpf.ama-assn.org/SearchML/searchDetails.action?uri=\%2FAMADoc\%2FHOD.xml-0-4119.xml.

12. Poździoch S. System zdrowotny. In: Czupryna A, Poździoch A, Ryś A, et al., eds. Zdrowie Publiczne. T. 1. Kraków: Vesalius; 2000: 127-144.

13. Poździoch S. System zdrowotny. In: Czupryna A, Poździoch A, Ryś A, i et al., eds. Zdrowie Publiczne. T. 1. Kraków: Vesalius; 2000: 134-135.

14. Declaration of Alma-Ata. International Conference on Primary Health Care, Alma-Ata, USSR, 6-12 September 1978 [cited 25.011.2007]. Avaible from URL: http://www.searo.who.int/LinkFiles/Health_Systems_declaration_almaata.pdf.

15. Targets for health for all. World Health Organization. Regional Office for Europe Copenhgen, Denmark. 1985: 103-106 [cited 28.04.2016]. Avaible from URL: http://www.euro.who.int/_data/assets/pdf_file/0006/109779/WA_540_GA1_85TA.pdf.

16. Komisja Wspólnot Europejskich: Komunikat Komisji dla Rady, Parlamentu Europejskiego, Europejskiego Komitetu Ekonomiczno-Społecznego i Komitetu Regionów. Wniosek dotyczący wspólnego sprawozdania 2007 w sprawie zabezpieczenia społecznego i integracji społecznej. KOM(2007) 13 wersja ostateczna. Bruksela 19 stycznia 2007 [cyt. 25.11.2007]. Dostępny na URL: http://eurlex.europa.eu.

17. Windak A, Godycki-Ćwirko M. Pryncypia medycyny rodzinnej. In: Latkowski BJ, Lukas W, eds. Medycyna rodzinna. Warszawa: Wydawnictwo Lekarskie PZWL; 2004: 17.

18. Fradgley EA, Paul CL. Consumer participation in quality improvements for chronic disease care: development and evaluation of an interactive patient-centered survey to identify preferred service initiatives. J Med Internet Res 2014; 16(12): 292.

19. Chen T-h, Li L, Kochen MM. A systematic review: how to choose appropriate health-related quality of life (HRQoL) measures in routine general practice? J Zhejiang Univ Sci B 2005; 6(9): 936-940.

20. Wells GA, Russell AS, Haraoui B, et al. Validity of quality of life measurement tools - from generic to disease-specific. J Rheumatol Suppl 2011; 88: 2-6.

21. Donabedian A. The quality of care. How can it be assessed? JAMA 1988; 260(12): 1743-1748.

22. Karaszewski R. Total Quality Management. Zarządzanie przez jakość. Wybrane zagadnienia. Toruń: TNOiK "Dom Organizatora"; 1999: 71.

23. PN-ISO 8402:1996. Zarządzanie jakością i zapewnienie jakości - Terminologia. Warszawa: Polski Komitet Normalizacyjny; 1996. 
Address for correspondence:

Krzysztof Kanecki, MD, PhD

Zakład Opieki Zdrowotnej

Katedra Medycyny Społecznej WUM

ul. Oczki 3

02-097 Warszawa

Polska

Tel.: +48 501 929-235

E-mail: kanecki@mp.pl

Received: 09.03.2016

Revised: 01.05.2016

Accepted: 19.05.2016 